\title{
Three Notch Multilayer Antenna for C-Band Applications
}

\author{
Sonal Trivedi \\ PG Student's NIIST Bhopal
}

\author{
Rajeev Thakur \\ Asst Prof NIIST \\ Bhopal
}

\author{
Saket Pandey \\ Asst Prof NIIST \\ Bhopal
}

\begin{abstract}
A three notch multilayer antenna for C-Band applications is presented in this paper. The proposed antenna is composed of a FR-4 and air gap Dielectric material, By introducing the two parts, the impedance bandwidth of the antenna can be significantly enhanced. Analysis done with ground plan. Simulation results show that the proposed antenna can operate from $3.2 \mathrm{GHz}$ to $4.8 \mathrm{GHz}$ with low VSWRs $\leq 2$. Stable antenna gain $(\mathrm{dB})$ is also achieved over the entire operating frequency band. Furthermore, the size of the proposed antenna is very compact, which is only at the centre of the operating frequency band.
\end{abstract}

\section{Keywords}

Broadband antenna, L-Slot, Radom, miniaturized antenna, square slot, C-Band.

\section{INTRODUCTION}

A variety of broadband techniques have been developed using the three approaches categorized. It is known that the factors affecting the bandwidth of a microstrip patch antenna are primarily the shape of the radiator, the feeding scheme, the substrate and the arrangements of radiating and parasitic elements. Essentially, the broad bandwidth of a microstrip patch antenna can be attributed to its low $Q$ value and simultaneously well excited multiple resonances. If the antenna is considered as a high-Q filter, lowering the $\mathrm{Q}$ by reducing the energy around the radiator or increasing losses broadens the bandwidth at its resonance. Alternatively, by inserting a broadband impedance network between the antenna and the feeder, good matching over a broad frequency range can be attained. If two or more adjacent modes are well excited simultaneously, the bandwidth can be twice or more than that for the single resonance. microstrip patch antenna having a larger sphere suffers from a narrow bandwidth as the whole volume of the enclosing sphere is not utilized effectively .Therefore, a microstrip patch antenna can be considered as a high-Q circuit, so one way to alleviate the narrow bandwidth problem is to reduce the $\mathrm{Q}$. Investigations have shown that the shape of a radiator affects the impedance bandwidth, even for the same maximum dimensions. However, the improvement in the bandwidth is quite limited.[7]-[9]. The shape of a radiator, which affects the operating modes is critical for its radiation performance. Therefore, this technique is hardly employed in practical designs [26]. As an alternative, a thick substrate with low dielectric constant is good for improving the impedance bandwidth of these antennas.[7][27-34].

This monotonically reduces the $\mathrm{Q}$ and broadens the bandwidth. Another important consideration is the increase in losses due to undesired surface waves, which lowers the radiation efficiency, excites spurious radiations, and degrades the radiation patterns. Investigations have shown that the impedance bandwidth monotonically increases with the substrate thickness while radiation efficiency rapidly decreases [7]. However, the achievable bandwidth will decrease when the thickness exceeds a certain value

\section{ANTENNA DESIGN AND CONFIGURATION}

The proposed design analyses with and without ground plan, analyses done by considering the effect of ground plan for enhancing bandwidth

\subsection{Antenna Design without Airgap}

The configuration of the proposed antenna is shown in Fig.1. The antenna is analyzed and optimized by IE3DTM software. The proposed antenna is composed of a FR-4 and air gap Dielectric material, The dimensions of design at $5 \mathrm{GHz}$ are

Top layer dimension is

$\mathrm{L}=17.77 \mathrm{~mm}, \mathrm{~W}=20 \mathrm{~mm}$

Middle layer dimension is

Bottom layer consists with ground plan, in first geometry analyses proposed design with effect of ground plan of dimension $\mathrm{Lg}=26.77 \mathrm{~mm}, \mathrm{Wg}=31 \mathrm{~mm}$. In second design analysis proposed antenna with multilayer combination FR-4Air - FR-4 consideration of effect of ground plan. Air gap is used for protection of radiation of antenna from atmospheric obstacle and radiation of other object

In fig 1 depicts Proposed Design Antenna with Ground Plan, in fig 2 depicts multilayer with ground plane.

\subsection{Numerical Analysis:}

The main objective of antenna analysis is to calculate all radiation characteristic of antenna. It is simple and possible to provide the proposed accuracy for impedance and radiation properties. There are three types of model available for analysis of antenna:

The Transmission line model.

The Cavity model.

The Full - wave model.

Equivalent dielectric constant for combination of two dielectrics can be calculated as:

$$
\varepsilon_{\mathrm{eq}}=\frac{\varepsilon_{\mathrm{r} 1} \varepsilon_{\mathrm{r} 2}\left(\mathrm{~h}_{1}+\mathrm{h}_{2}\right)}{\varepsilon_{\mathrm{r} 1} \varepsilon_{\mathrm{r} 2} h_{1}+\left(\mathrm{h}_{1}+\mathrm{h}_{2}\right)}
$$


Generally, the relationship of width (W), height (h), effective dielectric constant and relative dielectric constant of substrate is given as follow:

$$
\varepsilon_{\text {reff }}=\frac{\varepsilon_{\mathrm{r}}+1}{2}+\frac{\varepsilon_{\mathrm{r}-1}}{2}\left[1+12 \frac{\mathrm{h}}{\mathrm{W}}\right]^{\frac{1}{2}}
$$

The dimensions of patch along its length have now been extended on each end by the a distance $\Delta \mathrm{L}$, given by:

$$
\Delta \mathrm{L}=\frac{0.412 \mathrm{~h}\left(\varepsilon_{\text {reff }}+0.3\right)\left(\frac{\mathrm{W}}{\mathrm{h}}+0.264\right)}{\left(\varepsilon_{\text {reff }}-0.258\right)\left(\frac{\mathrm{W}}{\mathrm{h}}+0.8\right)}
$$

Since the effective length of the patch has been extended on both side by $\Delta \mathrm{L}$, the effective length is given by:

$$
\mathrm{L}=\mathrm{Leff}-2 \Delta \mathrm{L}
$$

For the effective radiation the design of the structure is the important aspect and for this width is calculated as:

$$
\mathrm{w}=\frac{\mathrm{c}}{2 \mathrm{f}_{0} \sqrt{\frac{\varepsilon \mathrm{r}+1}{2}}}
$$

\subsection{Basic design}

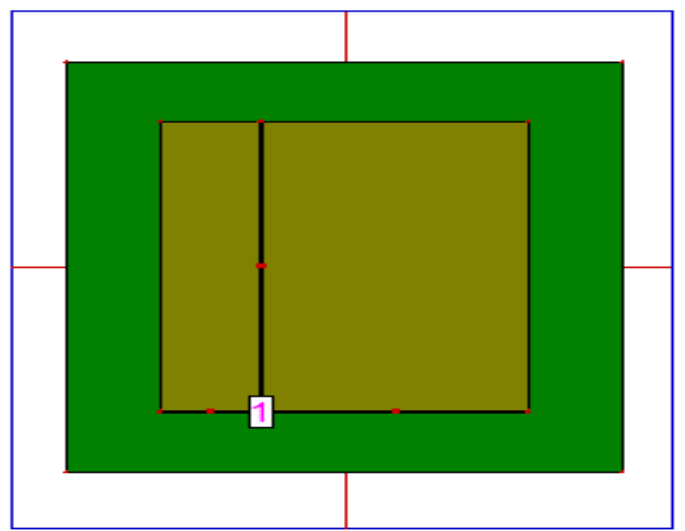

Figure 1 Proposed Multilayer Antenna Design

\subsection{Antenna Design with Air gap and multilayer}

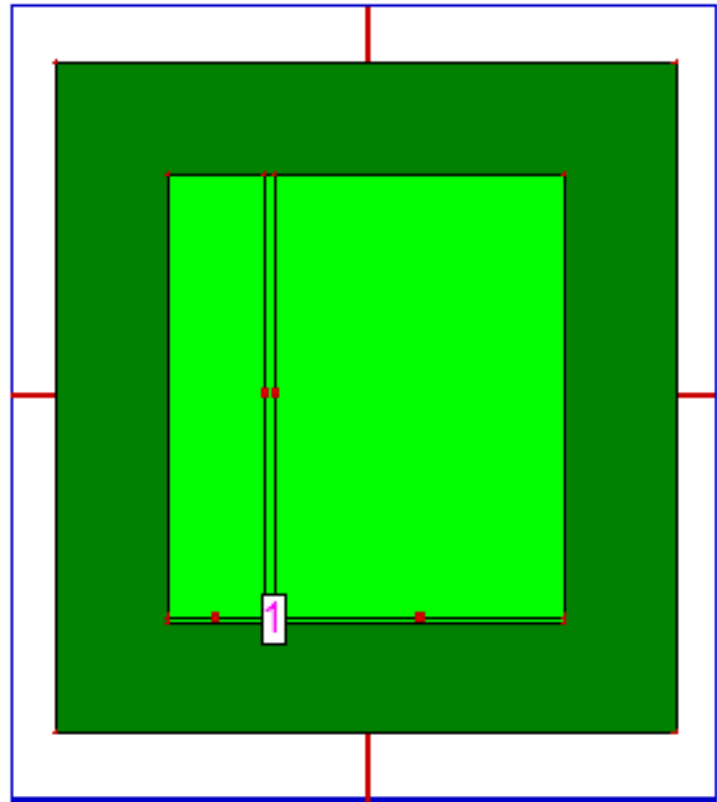

Figure 2 Antenna Design with Multilayer layer In fig 2 depicts Antenna Design with multilayer and airgap.

\section{RESUTS AND DISCUSSION}

\subsection{Antenna Design with Ground plan}

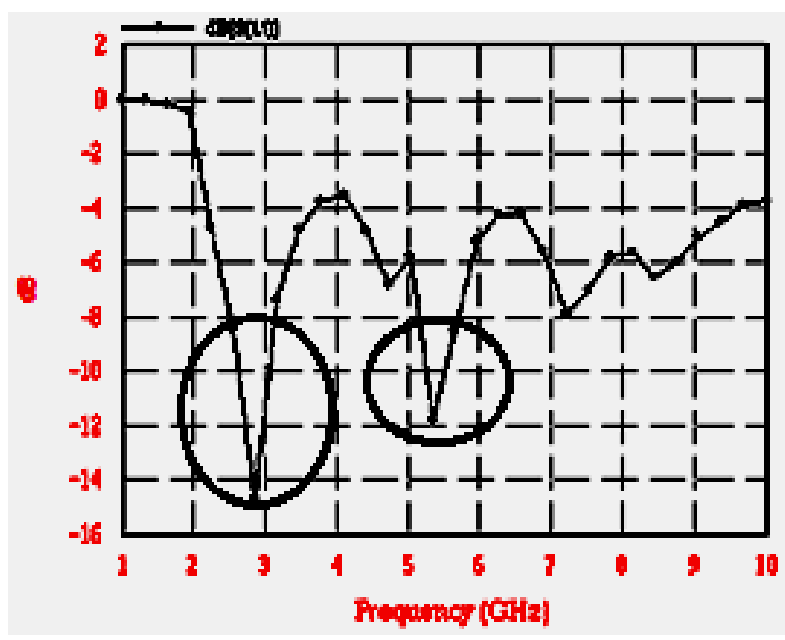

Figure 3 Return loss Vs Frequency

Fig 3 depicts Return loss of proposed design with respect to frequency. Firstly designed conventional design on IE3D Simulator, after simulation we found that reflection at $3 \mathrm{GHz}$ is low, return loss obtain up to $-15 \mathrm{~dB}$, and $-12 \mathrm{~dB}$, obtain at frequency $5.5 \mathrm{GHz}$. This is a theoretical design with respect to centre frequency but with respect to standard system results cannot be useable.

For effective useable design, required good impedance matching, for providing good impedance matching, used multilayer concept with air-gap. The appropriate dimension of ground plan is found using transmission line theory. The multilayer FR-4-Air-FR-4 Stack geometry discuss in section 3.2 . 


\subsection{Microstrip Multilayer Patch Antenna}

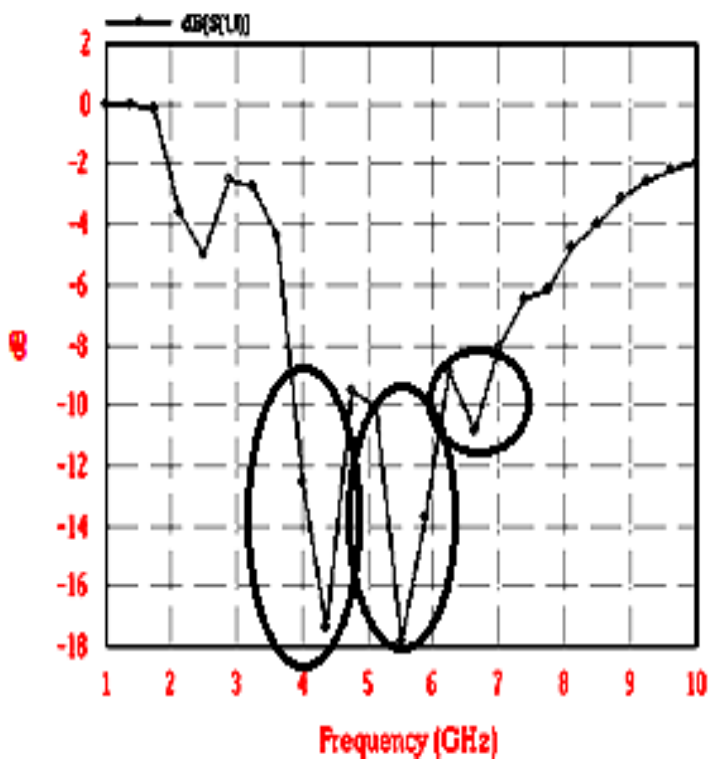

Figure 4 Return loss Vs Frequency

Fig 4 depicts Return loss of proposed design with respect to frequency. The proposed design on IE3D Simulator, after simulation found three notches in fig 4 , notches exists at $4.5 \mathrm{GHz}$ with $10 \%$ impedance bandwidth, at $5 . \mathrm{GHz}$ with $12 \%$ impedance bandwidth and $6.5 \mathrm{GHz}$, that reflection at $4.5 \mathrm{GHz}$ is low, return loss obtain up to $-17.5 \mathrm{~dB}$, and $-18 \mathrm{~dB}$ obtain at frequency $5.5 \mathrm{GHz}$. This is a proposed design with respect to centre frequency and applicable for C-Band application.

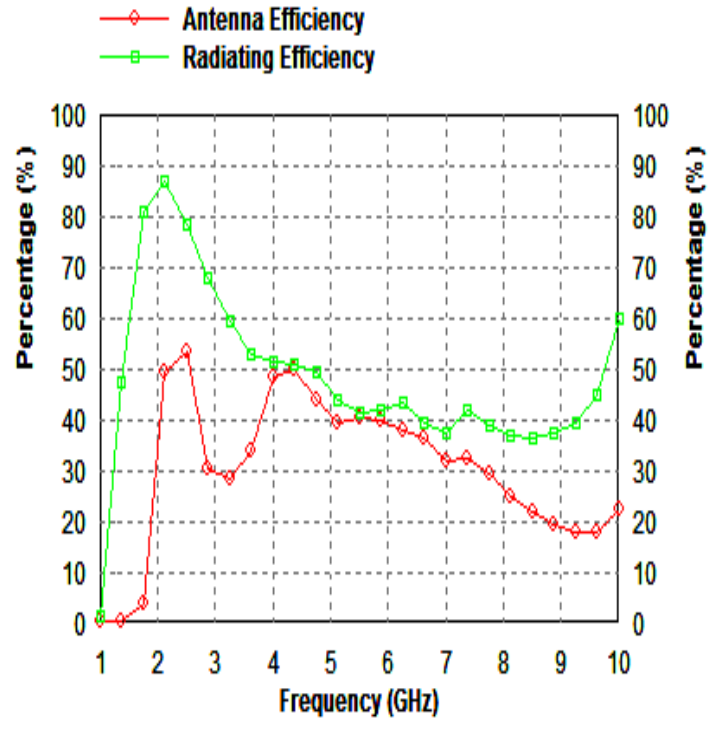

Figure 5 Efficiency Vs frequency

Fig 5 shows radiating and antenna efficiency for proposed design.

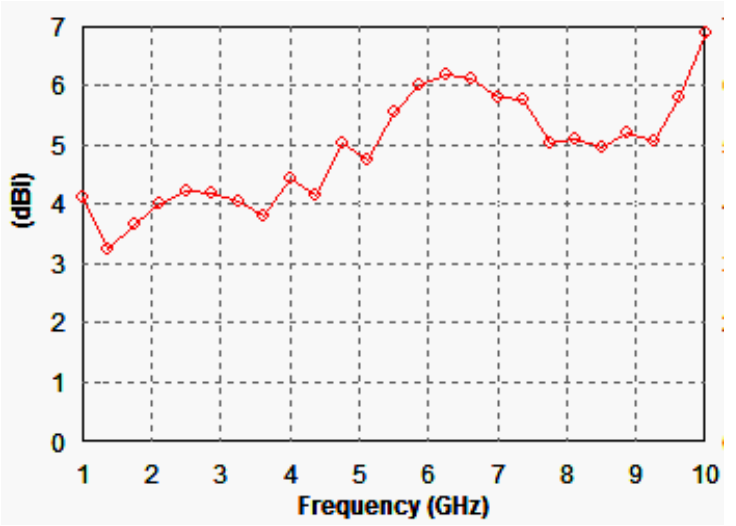

Figure 6 Directivity Vs Frequency

Fig 6 represents directive gain of antenna, obtain directivity up to $5.5 \mathrm{dBi}$.

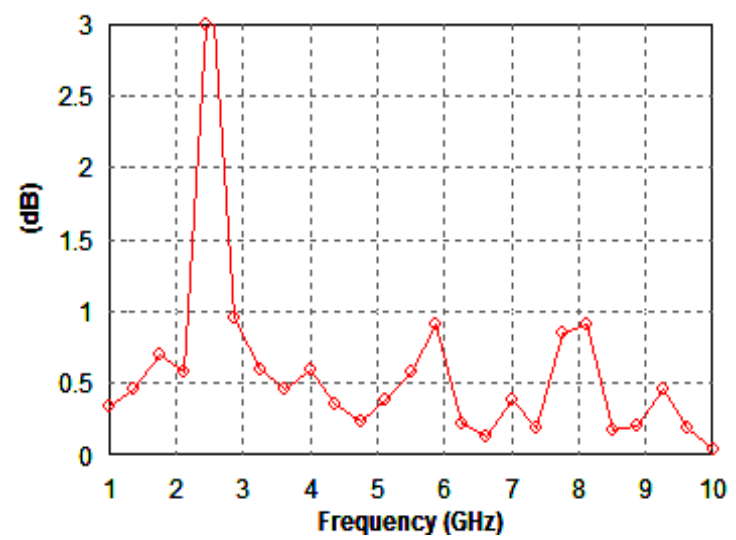

Figure 7 Axial Ratio Vs Frequency

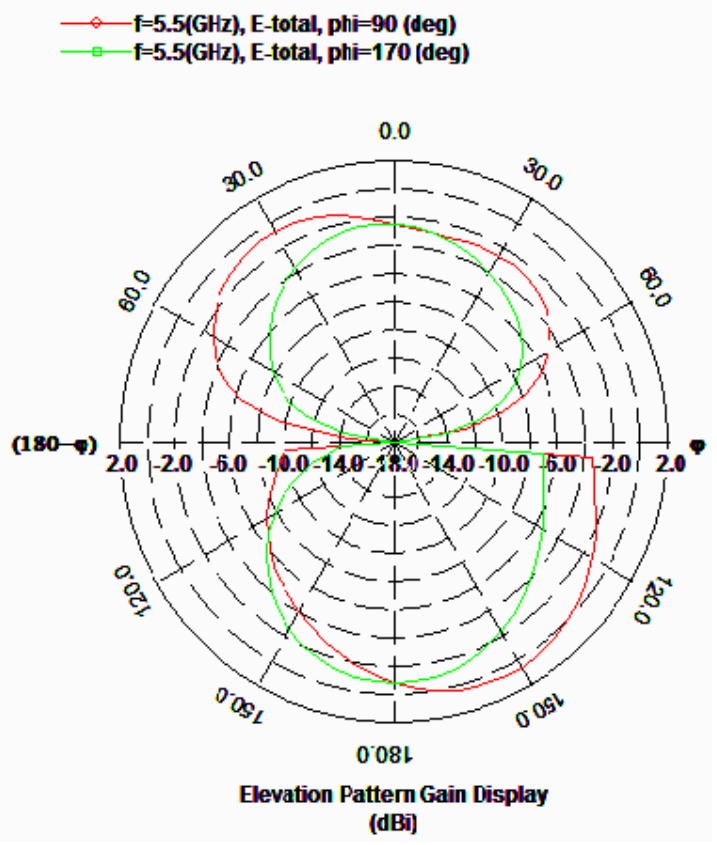

Figure 8 Elevation pattern at $5.5 \mathrm{GHz}$

Fig 7 represents polarization of antenna, for all three notches $4.5 \mathrm{GHz}, 5.5 \mathrm{GHz}$ and $6.5 \mathrm{GHz}$ axial ratio is less $1 \mathrm{~dB}$, So that antenna is circular polarized 


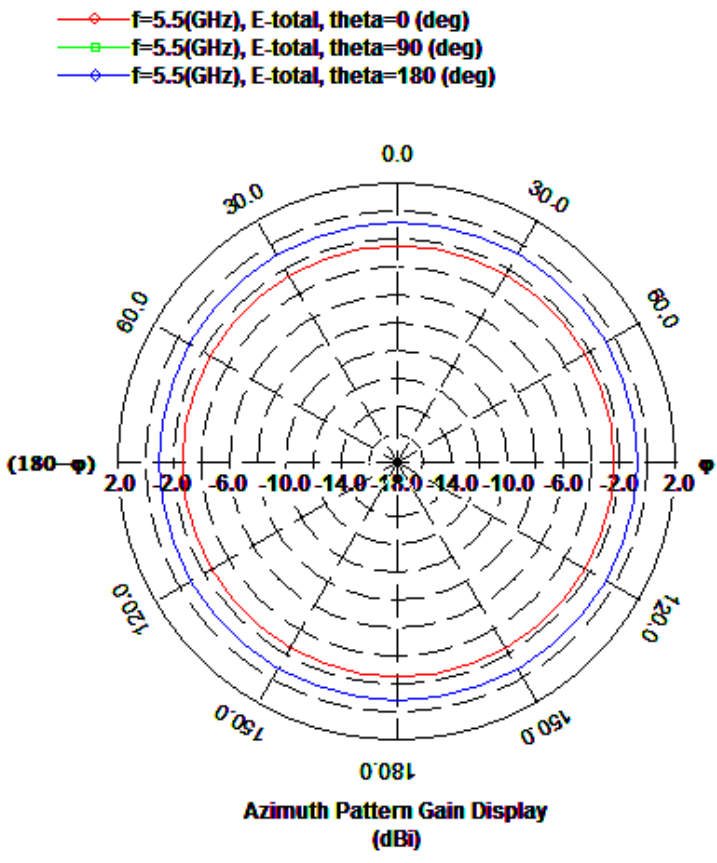

Figure 9 Azimuth pattern at $5.5 \mathrm{GHz}$

In fig $8 \& 9$, depicts elevation and azimuth pattern for proposed design with ground plan, in table summarized all results.

Table 1 Result Summary

\begin{tabular}{|c|c|}
\hline Frequency & $5.5(\mathrm{GHz})$ \\
\hline Input Power & $0.00983777(\mathrm{~W})$ \\
\hline Radiated Power & $0.0040479(\mathrm{~W})$ \\
\hline Average Radiated Power & $0.000322122(\mathrm{~W} / \mathrm{s})$ \\
\hline Radiation Efficiency & $41.1465 \%$ \\
\hline Antenna Efficiency & $40.479 \%$ \\
\hline \multicolumn{2}{|c|}{ Linear Properties } \\
\hline Linear Gain & $1.63694 \mathrm{dBi}$ \\
\hline Linear Directivity & $5.56464 \mathrm{dBi}$ \\
\hline Linear Maximum & at $(130,60) \mathrm{deg}$. \\
\hline 3dB Beam Width & $(57.4595,96.2808) \mathrm{deg}$ \\
\hline \multicolumn{2}{|c|}{ LH Circular Properties } \\
\hline Circular Gain & $-1.26924 \mathrm{dBi}$ \\
\hline Circular Directivity & $2.65846 \mathrm{dBi}$ \\
\hline Circular Maximum & at $(120,50) \mathrm{deg}$. \\
\hline 3dB Beam Width & $(52.4748,86.48)$ deg. \\
\hline
\end{tabular}

\section{CONCLUSION}

A three notch multilayer antenna for C-Band applications is presented in this paper. The proposed antenna is composed of a FR-4 and air gap dielectric material. For optimization transmission line model. Analysis done with and without airgap. From this analysis we concluded that appropriate dimensions of ground plan with air-gap severely effect the return loss impedance bandwidth and return loss, Simulation results show that the proposed antenna with ground can operate from $4.5 \mathrm{GHz}, 5.5 \mathrm{GHz}$ and $6.5 \mathrm{GHz}$ with low return less than $-10 \mathrm{~dB}$, by using AIR-GAP achieved $10 \%$ and $12 \%$ impedance bandwidth and $-18 \mathrm{~dB}$, Return loss at $5.5 \mathrm{GHz}$, Stable antenna gain $(5.5 \mathrm{dBi})$ is also achieved at $6.5 \mathrm{GHz}$ frequency. Furthermore, the size of the proposed antenna is very compact; the proposed antenna can be used for C-Band application.

\section{REFERENCES}

[1] I. J. Bahl and P. Bhartia, Microstrip Antennas. Dedham, MA: Artech House, 1980.

[2] J. R. James, P. S. Hall and C. Wood, Microstrip Antennas: Theory and Design. London: Peter Peregrinus (IEE), 1981.

[3] K. C. Gupta and A. Benalla, Microstrip Antenna Design. Norwood, MA: Artech House, 1988.

[4] J. R. James and P. S. Hall, Handbook of Microstrip Antennas. London: Peter Peregrinus (IEE), 1988.

[5] P. Bhartia, K. V. S. Rao and R. S. Tomar, Millimeterwave Microstrip and Printed Circuit Antennas. Boston,MA: Artech House, 1991.

[6] Y. T. Lo and E. S. W. Lee, Antenna Handbook. New York: Van Nostrand Reinhold, 1993.

[7] D. M. Pozar and D. H. S. (Ed.), Microstrip Antennas: Analysis and Design. New York: John Wiley \& Sons,lnc., 1995.

[8] K. F. Lee, K. M. Luk, K. F. Tong, S. M. Shum, T. Huynh and R. Q. Lee, 'Experimental and simulation studies of the coaxially fed U-slot rectangular patch antenna,' IEE Proceedings: Microwave, Antennas and Propagation, vol. 144, no. 5, pp. 354-358, 1997.

[9] R. Garg, P. Bhartia, I. Bahl and A. Ittipiboon, Microstrip Antenna Design Handbook. Boston, MA: Artech House, 2001.

[10] R. E. Munson, 'Conformal microstrip antennas and microstrip phased arrays,' IEEE Transactions on Antennas and Propagation, vol. 22, no. 1, pp. 74-78, 1974.

[11] J. W. Howell, 'Microstrip antennas,' IEEE Transactions on Antennas and Propagation, vol. 23, no. 1,p. 90-93, 1975.

[12] J. R. James, P. S. Hall, C. Wood and A. Henderson, 'Microstrip antennas,' IEEE Transactions on Antennas and Propagation, vol. 29, no. 1, pp. 124-128, 1981.

[13] K. R. Carver and J. W. Mink, 'Microstrip antenna technology,' IEEE Transactions on Antennas and Propagation, vol. 29, no. 1, pp. 2-24, 1981.

[14] R. Q. Lee, T. Huynh and K. F. Lee, 'Experimental study of the cross-polarization characteristics of rectangular patch antennas,' IEEE International Symposium on Antennas and Propagation, vol. 2, pp. 624-627, June 1989.

[15] N. Jayasundere and T. S. M. Maclean, 'Omni-directional radiation patterns from body-mounted microstrip antennas,' IEE Sixth International Conference on Antennas and Propagation, vol. 1, pp. 187-190, 4-7 April 1989.

[16] E. Levine, G. Malamud, S. Shtrikman and D. Treves, 'A study of microstrip array antennas with feed network, 'IEEE Transactions on Antennas and Propagation, vol. 37, no. 4, pp. 426-434, 1989.

[17] A. E. Gera, 'The radiation resistance of a microstrip element,' IEEE Transactions on Antennas and Propagation, vol. 38, no. 4, pp. 568-570, 1990. 
[18] Z. Nie, W. C. Chew and Y. T. Lo, 'Analysis of the annular-ring-loaded circular-disk microstrip antenna,'IEEE Transactions on Antennas and Propagation, vol. 38, no. 6, pp. 806-813, 1990.

[19] M. I. Aksun, S. L. Chuang and Y. T. Lo, 'On slotcoupled microstrip antennas and their applications to $\mathrm{cp}$ operation: theory and experiment,' IEEE Transactions on Antennas and Propagation, vol. 38, no. 8,pp. 1224-1230, 1990.
[20] D. R. Jackson and N. G. Alexopoulos, 'Simple approximate formulas for input resistance, bandwidth and efficiency of a resonant rectangular patch,' IEEE Transactions on Antennas and Propagation, vol. 39, no. 3,pp. 407-410, 1991.

[21] N. K. Das and D. M. Pozar, 'Multiport scattering analysis of general multilayered printed antennas fed by multiple feed ports. Part II: Applications,' IEEE Transactions on Antennas and Propagation, vol. 40, no. 5,pp. 482-491, 1992. 